\title{
Sistem Pendeteksi Alkohol Berbasis Sensor MQ-3 dan Internet of Things
}

\author{
Ade Rohdiana ${ }^{1}$ \\ Alviansyah Oktario Pratama \\ Rahma Rosaliana Saraswati ${ }^{3}$ \\ Universitas Negeri Jakarta \\ Email : ${ }^{1}$ aderohdiana97@gmail.com, ${ }^{2}$ alviansyah.op.22@gmail.com, ${ }^{3}$ rahma.rosaliana@gmail.com
}

\begin{abstract}
Today more and more food and beverages are mixed with some types of alcohol in disguise. Fatwa MUI No.4 Year 2003 states that " tidak boleh mengonsumsi dan menggunakan makanan/ minuman yang menimbulkan rasa/aroma (flavor) benda - benda atau binatang yang diharamkan". As per the current technological trend of Industrial Revolution 4.0. which focuses on internet-based technology using ESP8266 module so the researchers intend to make a detector of alcohol content that the results of its measurements can be known by real time by sending directly to the internet or known as Intenet of Things (IoT). This tool is expected to help the community, industry and government in determining the alcohol content of various products.
\end{abstract}

\section{Keywords : Alcohol, Sensor MQ-3, modul ESP8266}

\begin{abstract}
Abstrak
Dewasa ini semakin banyak makanan dan minuman yang dicampur dengan beberapa jenis alkohol secara terselubung. Fatwa MUI No.4 Tahun 2003 menyatakan bahwa "tidak boleh mengonsumsi dan menggunakan makanan/minuman yang menimbulkan rasa/aroma (flavor) benda - benda atau binatang yang diharamkan". Sesuai tren teknologi saat ini yaitu Revolusi Industri 4.0. yang menitik beratkan teknologi berbasis internet menggunakan modul ESP8266 maka peneliti bermaksud membuat alat pendeteksi kadar alkohol yang hasil pengukuran nya bisa diketahui dengan real time dengan langsung mengirimknannya ke internet atau dikenal dengan sebutan Intenet of Things (IoT). Alat ini diharpakan bisa membantu masyarakat, industri dan pemerintah dalam menentukan kadar alkohol dari berbagai produk.
\end{abstract}

\section{Kata kunci : Alkohol, Sensor MQ-3, modul ESP8266}

\section{Pendahuluan}

Mengonsumsi alkohol memiliki banyak dampak negatif. Jika dilihat dari segi sosial, mengonsumsi alkohol dapat menyebabkan orang - orang yang mabuk karena alkohol melakukan suatu tindak kejahatan. Kejaksaan Negeri Bandung mencatat sejak Januari hingga awal November 2015, perkara - perkara tindak pidana yang mencapai sekitar 1000 berkas, terugkap bahwa 50\% dari faktor - faktor kejahatan tersebut adalah karena pengaruh dampak buruk mengonsumsi miras.

Secara umumnya, kadar alkohol dalam makanan dari aspek kesehatan menetapkan bahwa seseorang dianggap sebagai mabuk jika kandungan alkohol dalam darahnya (BAC) mencapai 0.08 g/100ml. Namun demikian, tahap kadar pengambilan alkohol yang menyebabkan seseorang 
menjadi mabuk serta kadar kandungan alkohol yang diserap dalam darah adalah berbeda di antara satu individu dengan individu yang lain. (Ghani \& Ismail, 2010)

Dari segi kesehatan, mengonsumsi alkohol memiliki efek yang membahayakan bagi tubuh, yaitu, menyebabkan kepala berkunang - kunang, kehilangan koordinasi anggota tubuh, diare, muntah, buruknya kerja akal sehat dan kontrol diri, hilang ingatan atau kesadaran, penyakit jantung, kanker, dan sebagainya (Quamila, 2017). Menurut data Organisasi Kesehatan Dunia (WHO), setiap tahunnya di dunia lebih banyak orang tewas akibat konsumsi alkohol daripada akibat AIDS, TBC, dan kejahatan. Sekitar 3,3 juta jiwa tewas di tahun 2012 akibat mengonsumsi alkohol. Oleh karena efeknya yang memabukkan dan menyebabkan kercunan, Islam mengharamkan umatnya untuk mengkonsumsi alkohol. Sebagaimana yang tertuang dalam firman Allah dalam surat Al-Ma'idah (5) ayat 90-91.

Dewasa ini semakin banyak makanan dan minuman yang dicampur dengan beberapa jenis alkohol secara terselubung. Contohnya, bir untuk pengencer adonan untuk menggoreng ikan, ang ciu digunakan sebagai campuran tumisan pada masakan cina, sake yang biasanya digunakan untuk campuran saus teriyaki, wine, bourbo, atau kirsch banyak digunakan dalam french cooking (terutama dalam sausnya), red wine yang digunakan untuk membuat fruit cake dan rum yang digunakan sebagai penguat rasa untuk kue. Rum sendiri merupakan hasil destilasi air tebu atau yang biasa kita kenal dengan molase. Alkohol yang dihasilkan dari proses ini cukup tinggi yaitu sekitar 38\% (Filda, 2003).

Sesuai dengan sabda Rasulullah, yang diriwayatkan oleh Abu Daud, At - Tirmidzi, AnNasa'i, dan Ibnu Majah, "sesuatu yang apabila banyaknya memabukkan, maka meminum sedikitnya dinilai haram". Oleh karena itu, Fatwa MUI No.4 Tahun 2003 menyatakan bahwa "tidak boleh mengonsumsi dan menggunakan makanan/ minuman yang menimbulkan rasa/aroma (flavor) benda benda atau binatang yang diharamkan".

Pada penelitian sebelumnya sudah banyak yang membuat penelitian serupa, misalnya Magfirah tahun 2012 dengan judul Sistem Kontrol Pengukur Kadar Alkohol Pada Cairan Berbasis Mikrokontroler Atmega8535, dalam penelitian tersebut masih memiliki kekurangan lalu peneliti tersebut menyarankan agar terus dikembangkan salah satunya adalah dengan mengembangkan proses pengiriman hasil pengukuran ke data base.

Sesuai tren teknologi saat ini yaitu Revolusi Industri 4.0. yang menitik beratkan teknologi berbasis internet maka peneliti bermaksud membuat alat pendeteksi kadar alkohol berbasis sensor MQ-3 dan Internet of Things yang hasil pengukuran nya bisa diketahui dengan real time dengan langsung mengirimkannya ke internet atau dikenal dengan sebutan Intenet of Things (IoT). Alat ini diharapakan bisa membantu masyarakat, industri dan pemerintah dalam menentukan kadar alkohol dari berbagai produk. Tidak hanya rum pada kue saja.

\section{Metode Penulisan}

Dalam Penelitian ini menggunakan pendekatan kualitatif. Dengan teknik pengumpulan data yaitu studi pustaka dan observasi. Studi Pustaka dilakukan dengan mengumpulkan data dengan cara membaca dari berbagai literatur seperti artikel ilmiah, jurnal, internet, buku, dan bahan bacaan lainnya yang berkaitan dengan pembahasan penelitian. Observasi yaitu melakukan pengamatan secara langsung di lokasi penelitian terhadap obyek yang akan diteliti dan dibahas serta mengumpulkan data atau informasi sebanyak mungkin yang berhubungan dengan masalah yang akan diteliti (Magfirah, 2012). 


\section{Hasil dan Pembahasan}

Analisis Solusi yang Pernah Diterapkan berupa upaya pemerintah dalam mengatasi penyebaran makanan atau minuman yang mengandung alkohol adalah dengan membuat Undangundang Republik Indonesia nomor 33 tahun 2014 tentang jaminan produk halal. Adanya undangundang tersebut sangat membantu masyarakat Indonesia khususnya umat muslim dalam menentukan makanan apa saja yang halal dan dapat dimakan. Penempelan logo halal biasanya pada kemasan dari produk tersebut namun masih ada saja oknum yang masih menjual produk makanan yang didalamnya ada kandungan alkohol.

Untuk mengatasi hal itu dibutuhkan alat yang dapat membantu masyarakat dalam mendeteksi kadar alkohol dalam makanan Pada penelitian sebelumnya sudah banyak peneliti yang membuat penelitian untuk meminimalisir fenomena seperti itu, misalnya hasil penelitian dari I Gede Bagus Arya yang berjudul Perancangan Alat Ukur Kadar Alkohol Menggunakan Sensor Mq3 Berbasis Mikrokontroler Atmega16. Dari hasil penelitian yang diperoleh dan pembahasan yang telah diuraikan telah berhasil dirancang alat ukur kadar alkohol, maka dapat ditarik kesimpulan sensor MQ-3 memiliki karakteristik dimana sensor mempunyai sensitifitas tinggi terhadap gas alkohol serta tegangan keluaran sebanding dengan perubahan kadar gas alkohol yang dideteksi, menghabiskan daya sebesar $500 \mathrm{~mW}$ dan waktu pemanasan sensor selama 10 menit. Kesesuaian alat rancangan yang diperoleh dari hasil analisa regresi linier data pengujian alat rancangan yaitu sebesar 99,57\%. Persamaan penelitian diatas dengan penelitian penulis adalah penggunaan sensor MQ-3 sebagai pendeteksi kadar alkohol. Hasil Penelitian dari Prasetyo yang berjudul Rancang Bangun Alat Ukur Kadar Alkohol Pada Minuman Menggunakan Sensor Gas MQ3. Hasil penelitian dari alat pendeteksi kadar alkohol berhasil mendeteksi kadar alkohol dan menggolongkan minuman sesuai dengan Peraturan Menteri Kesehatan Republik Indonesia No.86/1977, dengan rata - rata persentase kesalahan sebesar 4.7 \%. Magfirah tahun 2012 dengan judul Sistem Kontrol Pendeteksi Kadar Alkohol Pada Cairan Berbasis Mikrokontroler Atmega8535, dalam penelitian tersebut masih memiliki kekurangan lalu peneliti tersebut menyarankan agar terus dikembangkan salah satunya adalah dengan mengembangkan proses pengiriman hasil pendeteksian ke data base. Dari berbagai penelitian diatas tidak pernah ada satupun yang diterapkan di masyarakat, padahal masyarakat sangat membutuhkan sekali alat tersebut.

\section{Hasil Pembuatan alat}

Langkah pertama yang harus dilakukan adalah mengetahui bahan-bahan apa saja yang dibutuhkan dalam proses pembuatan tersebut. Bahan yang dibutuhkan adalah sebagai berikut:

Tabel 1. Bahan pembuatan alat

\begin{tabular}{|r|l|}
\hline \multicolumn{1}{|l|}{ NO } & Nama Bahan \\
\hline 1 & Laptop \\
\hline 2 & Timbangan \\
\hline 3 & Sensor MQ-3 \\
\hline 4 & Modul ESP8266 \\
\hline 5 & LCD $16 \times 2$ \\
\hline
\end{tabular}




\begin{tabular}{|r|l|}
\hline 6 & Kabel Jumper \\
\hline 7 & Batere $12 \mathrm{~V}$ \\
\hline 8 & Regulator \\
\hline
\end{tabular}

Sensor yang dipakai pada alat ini adalah sensor MQ-3. Sensor MQ-3 memiliki nilai resistansi Rs, yang nilainya dapat berubah bila mendeteksi gas alkohol di udara. Rangkaian terdiri dari 1 buah variabel resistor dan pin $\mathrm{H}$ yang dihubungkan dengan tegangan sebesar $5 \mathrm{~V}$ (I Gede, 2017).

Sensor gas alkohol MQ-3 harganya lebih murah dibanding dengan jenis sensor gas alkohol lainnya, dengan sensitivitas sensor yang hampir sama. Hanya saja sensor MQ-3 ini mengkonsumsi daya yang cukup besar dibandingkan dengan jenis sensor gas alkohol lainnya, yaitu sekitar 750 $\mathrm{mW}$. Disamping itu pemilihan sensor MQ-3 didasarkan pada pertimbangan sebagai berikut :

- Kepekaan terhadap alkohol yang tinggi dan rendah terhadap bensin,

- Waktu respon cepat,

- Stabil dan tahan lama,

- Sumber tegangan AC atau DC 5 Volt,

- Suhu Operasional -10 s/d 70 derajat Celcius
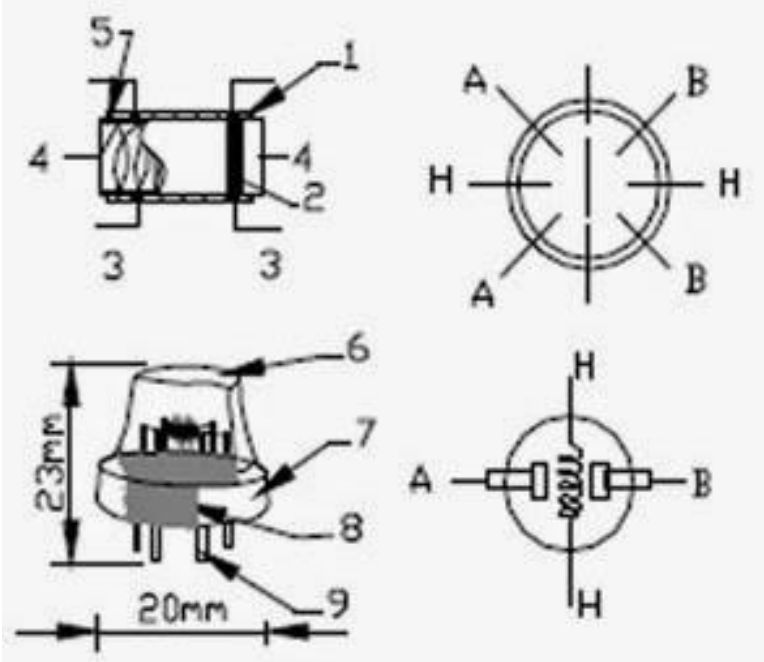

Gambar 1. Dimensi Sensor MQ-3

Elemen sensor MQ-3 terdiri atas lapisan kristal metaloksida (SnO2) dengan konduktivitas yang kecil dalam udara bersih. Resistansi sensor akan berubah-rubah seiring dengan terdeteksinya 
keberadaan gas alkohol (etanol) oleh elemen sensor. Jika konsentrasi etanol tinggi, maka resistansi sensor akan berkurang sehingga tegangan keluaran akan meningkat. Ketika kristal metal oksida (SnO2) pada kondisi normal yaitu pada suhu kamar, permukaan bahan metal oksida $(\mathrm{SnO} 2)$ berinteraksi dengan molekul-molekul oksigen yang ada di udara. Atom-atom oksigen akan terabsorpsi dan mengikat elektron bebas yang terdapat pada permukaan metal oksida (SnO2). Di dalam sensor gas, arus listrik mengalir melewati daerah sambungan (grain boundary) dari kristal $\mathrm{SnO}$. Pada daerah sambungan, penyerapan oksigen mencegah muatan untuk bergerak bebas. Jika konsentrasi gas menurun, proses dioksidasi akan terjadi. Rapat permukaan dari muatan negatif oksigen akan berkurang dan akan mengakibatkan menurunnya ketinggian penghalang dari daerah sambungan. Dengan menurunnya penghalang maka resistansi sensor juga akan ikut menurun.

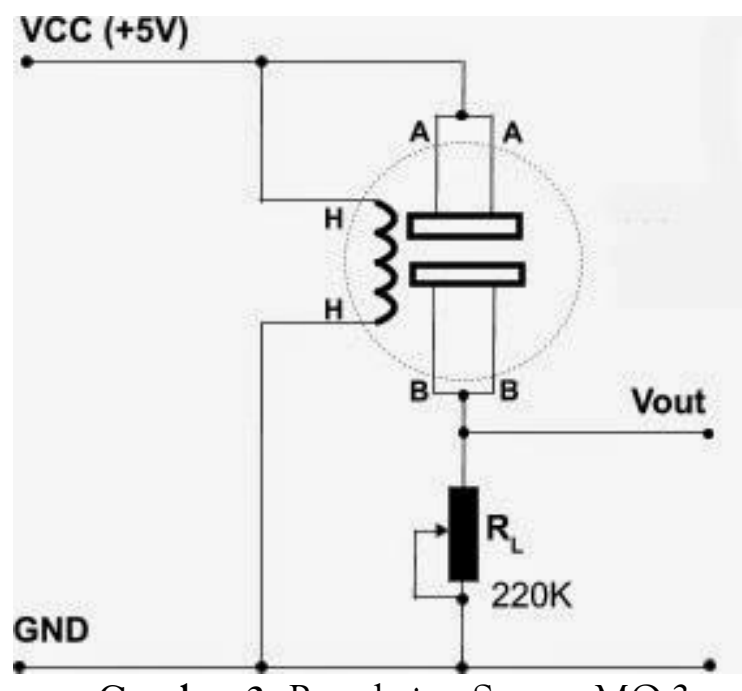

Gambar 2. Rangkaian Sensor MQ-3

Sensor gas alkohol MQ-3 adalah sensor yang cocok untuk mendeteksi kadar alkohol secara langsung, misalnya kadar alkohol pada napas kita. Driver untuk sensor MQ-3 ini sangat sederhana, hanya memerlukan 1 buah resistor variabel. Output sensor MQ-3 dalam bentuk tegangan analog yang sebanding dengan kadar alkohol yang diterima. Interfaxe yang diperlukan juga cukup sederhana, bisa menggunakan ADC yang dapat merespon tegangan 0 volt - 3,3 volt. Nilai resistor yang dipsang pada sensor MQ-3 harus dibedakan terhadap berbagai jenis dan konsentrasi gas yang ada dalam udara bersih, sehingga pada saat menggunakannya perlu dilakukan penyesuaian. Jadi perlu dikalibrasi untuk 0,4 $\mathrm{mg} / \mathrm{L}$ (sekitar $200 \mathrm{ppm}$ ) konsentrasi alkohol di udara dan pada resistansi output sekitar $200 \mathrm{~K} \Omega(100 \mathrm{~K} \Omega \mathrm{s} / \mathrm{d} 470 \mathrm{~K} \Omega$ ) (Margiono, 2015). 


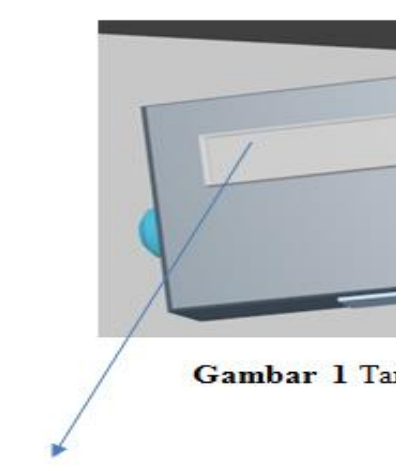

lod



Gambar 3. Grafik Karakteristik Sensor MQ-3

Keterangan :

Rs $=$ Sensor resistance in displayed gases at various concentrations Ro $=$ Sensor resistance in $200 \mathrm{ppm}$ of ethanol

Tabel 2. Karakteristik Sensor MQ-3

\begin{tabular}{|c|c|c|c|}
\hline \multicolumn{3}{|c|}{ Model No. } & MQ-3 \\
\hline \multicolumn{3}{|c|}{ Sensor Type } & Semiconductor \\
\hline \multicolumn{3}{|c|}{ Standard Encapsulation } & Bakelite (Black Bakelite) \\
\hline \multicolumn{3}{|c|}{ Detection Gas } & Alcohol gas \\
\hline \multicolumn{3}{|c|}{ Concentration } & $0.04-4 \mathrm{mg} / \mathrm{l}$ alcohol \\
\hline \multirow{3}{*}{ Circuit } & Loop Voltage & $V_{c}$ & $\leq 24 \mathrm{~V} \mathrm{DC}$ \\
\hline & Heater Voltage & $V_{H}$ & $5.0 \mathrm{~V} \pm 0.2 \mathrm{~V} \mathrm{AC}$ or $\mathrm{DC}$ \\
\hline & Load Resistance & $R \mathrm{~L}$ & Adjustable \\
\hline \multirow{5}{*}{ Character } & Heater Resistance & $\mathrm{RH}$ & $31 \Omega \pm 3 \Omega$ Room Tem. \\
\hline & Heater consumption & $\mathrm{PH}$ & $\leq 900 \mathrm{~mW}$ \\
\hline & Sensing Resistance & $R_{s}$ & $2 \mathrm{~K} \Omega-20 \mathrm{~K} \Omega$ (in $0.4 \mathrm{mg} / \mathrm{l}$ alcohol ) \\
\hline & Sensitivity & s & $\operatorname{Rs}$ (in air)/Rs $(0.4 \mathrm{mg} / \mathrm{L}$ Alcohol) $\geq 5$ \\
\hline & Slope & $\alpha$ & $\leq 0.6(\mathrm{R} 300 \mathrm{ppm} / \mathrm{R} 100 \mathrm{ppm}$ Alcohol) \\
\hline \multirow{3}{*}{ Condition } & Tem. Humidity & & $20 \pm 265 \% \pm 5 \%$ RH \\
\hline & \multicolumn{2}{|c|}{ Standard test circuit } & $\begin{array}{l}\text { Vc:5.0V } \pm 0.1 \mathrm{~V} \\
V_{H}: 5.0 \mathrm{~V} \pm 0.1 \mathrm{~V}\end{array}$ \\
\hline & \multicolumn{2}{|l|}{ Preheat time } & Over 48 hours \\
\hline
\end{tabular}

Setelah mengetahui bahan apa saja yang dibutuhkan, langkah selanjutnya adalah merancang desain dari alat tersebut. Desain tersebut dirancang dengan gambar 3D. Berikut adalah desain alat pendeteksi kadar alkohol berbasis sensor MQ-3 dan Internet of Things. 
Gambar 4. Desain Alat

Setelah desain alat dibuat, langkah berikutnya adalah merangkai dan memprogram alat tersebut agar bisa mendeteksi kadar alkohol dalam makanan kemudian hasil dari deteksinya di tampilkan di display. Program yang dibuat menggunakan software Arduino IDE.

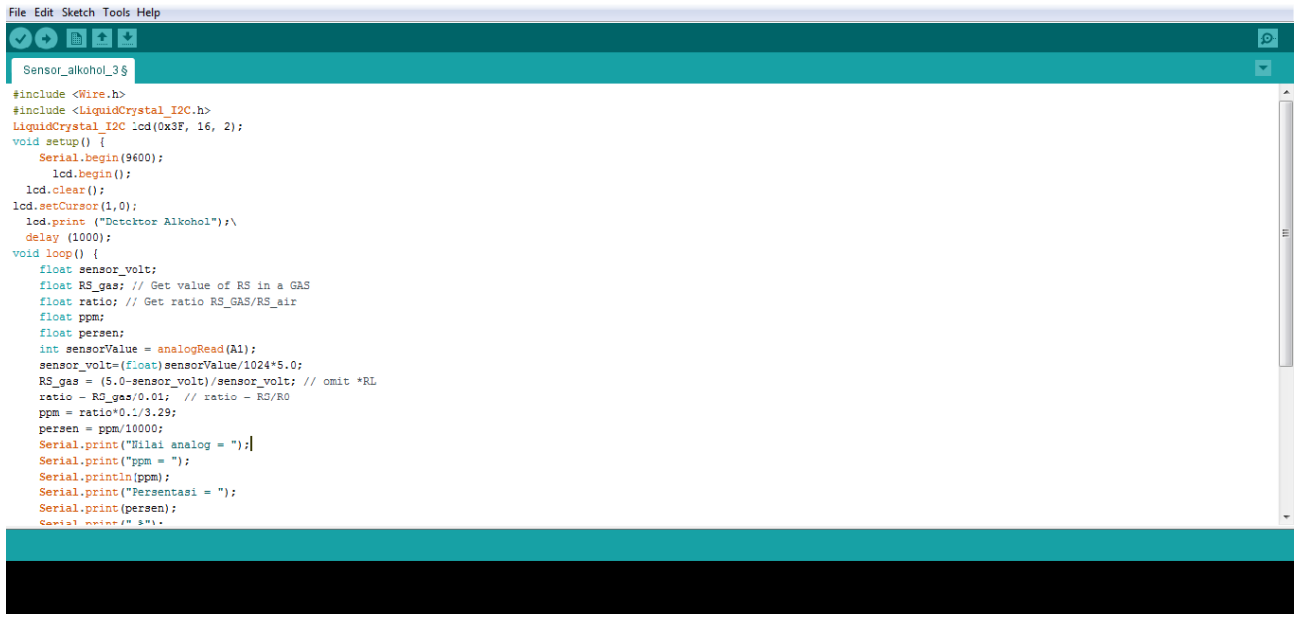

Gambar 5. Program alat

Program yang dibuat kemudian di upload ke komponen mikrokontroler, setelah itu melakukan kalibrasi pada alat tersebut. Kalibrasi pada alat ini yaitu dapat mendeteksi alkohol dengan kadar 20\% - 96\%. Untuk mendapatkan alkohol dengan kadar rendah di pasaran, penulis melakukan pegenceran terhadap akohol yang ada.

Dengan cara, menghitung rumus yaitu :

Dengan keterangan :

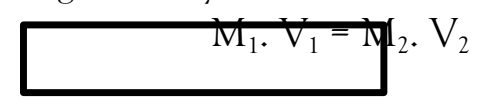

$\mathrm{M}_{1}=$ molaritas/konsentrasi larutan yang diketahui

$\mathrm{V}_{1}=$ volume larutan yang diketahui

$\mathrm{M}_{2}=$ molaritas/konsentrasi larutan yang diinginkan

$\mathrm{V}_{2}=$ volume larutan yang diinginkan

Selain kalibrasi membandingkan dengan rumus. Kalibrasi juga dilakukan dengan membandingkan hasil pengukuran kadar alkohol antara alat yang dibuat dengan Alkohol Tester. Setelah melakukan kalibrasi tahap selanjutnya adalah telemetri data. Telemeteri didefiniskan pengukuran suatu variabel yang memungkinkan dilakukan jarak jauh, dalam gagasan kali ini telemeteri yang dilakukan adalah mengukur kadar alkohol pada makanan kemudian data hasil pengukuran tersebut dikirim melalui internet dan di tampilkan di layar ponsel android.

Kontroller dan komunikasi data via wifi dilakukan dengan menggunan Modul ESP8266. Modul ESP8266 adalah sebuah komponen chip terintegrasi yang didesain untuk keperluan dunia masa kini yang serba tersambung. Chip ini menawarkan solusi networking Wi-Fi yang lengkap dan menyatu, yang dapat digunakan sebagai penyedia aplikasi atau untuk memisahkan semua fungsi 
networking Wi-Fi ke pemproses aplikasi lainnya. ESP8266 memiliki kemampuan on-board prosesing dan storage yang memungkinkan chip tersebut untuk diintegrasikan dengan sensorsensor atau dengan aplikasi alat tertentu melalui pin input output hanya dengan pemrograman singkat.

Modul komunikasi WiFi dengan IC SoC ESP8266EX Serial-to-WiFi Communication Module ini merupakan modul WiFi dengan harga ekonomis. Kini dapat menyambungkan rangkaian elektronika ke internet secara nirkabel karena modul elektronika ini menyediakan akses ke jaringan WiFi secara transparan dengan mudah melalui interkoneksi serial (UART RX/TX)

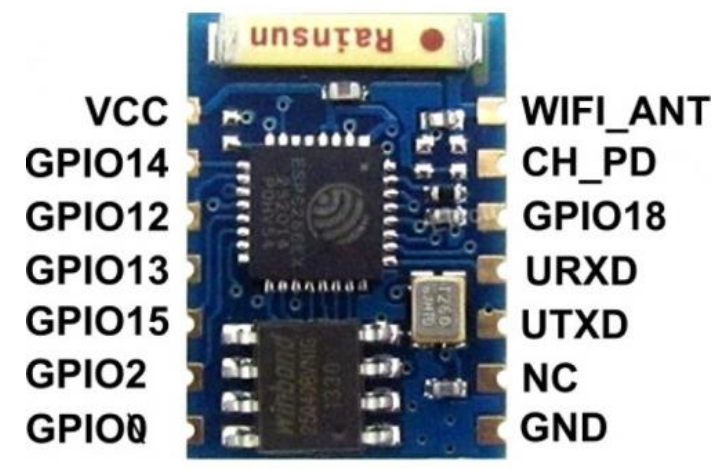

Gambar 6. modul esp8266

Keunggulan utama modul ini adalah tersedianya mikrokontroler RISC (Tensilica 106 $\mu$ Diamond Standard Core LX3) dan Flash Memory SPI 4 Mbit Winbond W2540BVNIG terpadu, dengan demikian Anda dapat langsung menginjeksi kode program aplikasi langsung ke modul ini. Fitur SoC ESP8266EX:

- Mendukung protokol $802.11 \mathrm{~b} / \mathrm{g} / \mathrm{n}$

- WiFi Direct (P2P / Point-to-Point), Soft-AP / Access Point

- TCP/IP Protocol StackterpaduMendukung WEP, TKIP, AES, dan WAPI

- Pengalih T/R, balun, LNA (penguat derau rendah) terpadu

- Power Amplifier / penguat daya $24 \mathrm{dBm}$ terpadu

- Sirkuit PLL, pengatur tegangan, dan pengelola daya terpadu

- Daya keluaran mencapai +19,5 dBm pada moda 802.11 b

- Sensor suhu internal terpadu

- Mendukung berbagai macam antenna

- Kebocoran arus pada saat non-aktif kurang dari $10 \mu \mathrm{A}$

CPU mikro 32-bit terpadu yang dapat digunakan sebagai pemroses aplikasi lewat antarmuka iBus, dBus, AHB (untuk akses register), dan JTAG (untuk debugging)

- Antarmuka SDIO 2.0, SPI, UART

- $\mathrm{STBC}, 1 \times 1 \mathrm{MIMO}, 2 \times 1 \mathrm{MIMO}$

- Agregasi A-MPDU dan A-MSDU dengan guard interval0,4 $\mu \mathrm{s}$

- Waktu tunda dari moda tidur hingga transmisi data kurang dari 2 ms

Modul WiFi ini bekerja dengan catu daya 3,3 volt. Salah satu kelebihan modul ini adalah kekuatan transmisinya yang dapat mencapai 100 meter, dengan begitu modul ini memerlukan koneksi arus yang cukup besar (rata-rata $80 \mathrm{~mA}$, mencapai $215 \mathrm{~mA}$ pada CCK $1 \mathrm{MBps}$, moda 
transmisi $802.11 \mathrm{~b}$ dengan daya pancar $+19,5 \mathrm{dBm}$ belum termasuk $100 \mathrm{~mA}$ untuk sirkuit pengatur tegangan internal). Sedangkan untuk menampilkan hasil pengukuran menggunakan aplikasi android yang bernama Blynk.

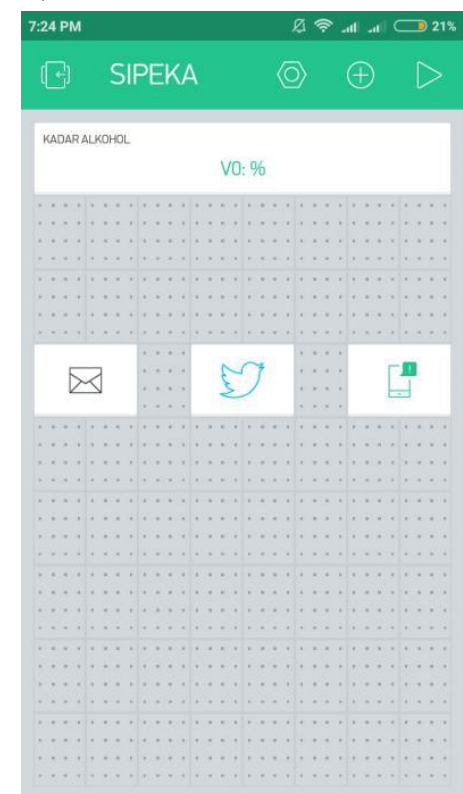

Gambar 7. Tampilan display Blynk

\section{Analisis Implementasi Penerapan Alat Kepada Masyarakat}

Untuk membuat dan menerapkan SIPEKA (Sistem Pendeteksi Kadar Alkohol Berbasis Sensor Mq-3 Dan Internet Of Things) membutuhkan peran secara kolaboratif dari berbagai sektor, diantaranya adalah pemerintah sebagai regulator, akademisi sebagai konseptor berbasis keilmuan dan lahirnya ide-ide kreatif, dan juga sektor bisnis. Peran kolaboratif tersebut tentunya tidak terbentuk instan, namun memerlukan proses yang konsisten dan sistematis, mulai dari sosialisasi, persuasi, hingga implementasi.

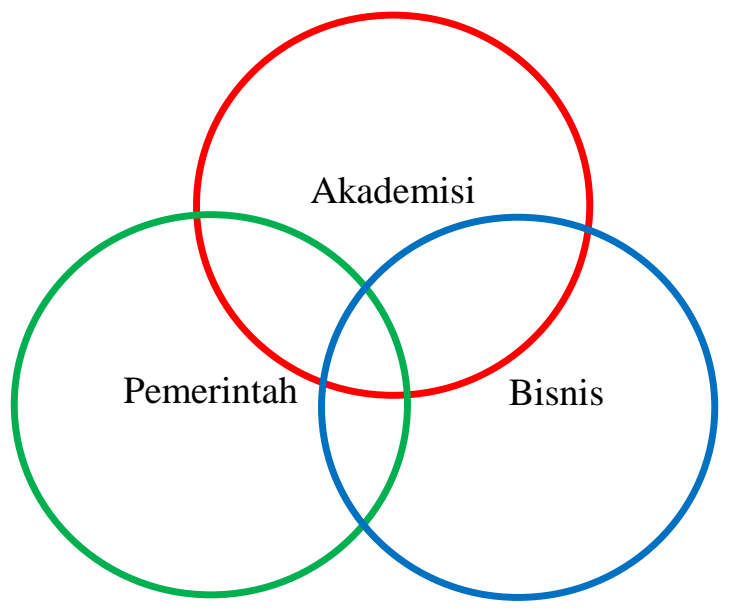

Gambar 8. Diagram kolaboratif

Langkah strategis yang digunakan dalam implementasi gagasan ini, dirumuskan berdasarkan analisis SWOT. Berikut merupakan hasil analisis SWOT konsep green small island 
disajikan dalam Tabel 3.

Tabel 3. Analisis SWOT

\begin{tabular}{|c|c|}
\hline Kekuatan (Strenght) & Peluang (Opportunities) \\
\hline $\begin{array}{l}\text { 1. Banyak akademisi dibidang } \\
\text { Teknologi } \\
\text { 2. Memiliki sektor bisnis dan } \\
\text { pemerintahan yang mendukung } \\
\text { dibidang teknologi }\end{array}$ & $\begin{array}{l}\text { 1. Meminimalisir } \\
\text { makanan beralkohol } \\
\text { 2. Berkembangnya teknologi } \\
\text { Internet of Things di Indonesia } \\
\text { 3. Berperan aktif berdakwah } \\
\text { tentang makanan halal dan } \\
\text { haram } \\
\text { 4. Menarik investor } \\
\text { 5. Indonesia memiliki jumlah } \\
\text { penduduk muslim terbanyak di } \\
\text { Dunia }\end{array}$ \\
\hline $\begin{array}{l}\text { Kelemahan (Weakness) } \\
\text { 1. Keterbatasan dana } \\
\text { 2. Memerlukan proses yang lama }\end{array}$ & $\begin{array}{l}\text { Ancaman (Threats) } \\
\text { 1. Prilaku masyarakat yang sulit } \\
\text { adaptasi } \\
\text { 2. Kurang menjadi prioritas } \\
\end{array}$ \\
\hline
\end{tabular}

\section{Kesimpulan}

Tren teknologi saat ini yaitu Revolusi Industri 4.0. yang menitik beratkan teknologi berbasis internet maka alat pendeteksi kadar alkohol yang hasil pendeteksiannya bisa diketahui dengan real time dengan langsung mengirimkannya ke internet atau dikenal dengan sebutan Intenet of Things (IoT) dapat menjadi solusi yang tepat untuk membantu masyarakat, industri dan pemerintah dalam menentukan kadar alkohol dari berbagai produk dengan mudah.

\section{Saran}

Berdasarkan penelitian di atas, maka peneliti memberikan saran kepada peneliti selanjutnya untuk mengadakan penelitian mengenai pengembangan alat pendeteksi babi pada makanan. Hal ini dikarenakan sama dengan alkohol, mengonsumsi babi juga hukumnya haram dan berbahaya bagi kesehatan. Akan tetapi peredaran makanan yang mengandung babi telah menyeba luas di masyarakat.

\section{Daftar Pustaka}

Dwi, Agung. (2016). Rancang Bangun Kadar Alkohol pada Minuman Menggunakan Sensor Gas MQ-3 Berbasis Mikrokontroller Arduino Uno. UIN Sunan Kalijaga. Yogyakarta.

Ghani, A. A., \& Ismail, M. S. (2010). Penetuan Piawaian Alkohol Dalam Makanan yang Dibenarkan Dalna. Journal of Fiqh No.7, 277-299. 
I Gede Surya. (2017). Perancangan Alat Ukur Kadar Alkohol Menggunakan Sensor Mq-3 Berbasis Mikrokontroler Atmega16. Universitas Udayana. Bali.

Jauhari. (2014). Nafkah dalam Perspektif Al - Qur'an. Tesis, UIN Sunan Ampel Surabaya.

Maghfirah. (2012). Sistem Kontrol Pengukur Kadar Alkohol Pada Cairan Berbasis Mikrokontroler Atmega8535. Makassar: UIN Alauddin.

Sugiyono. (2016). Metode Penelitian Kuantitatif, Kualitatif, dan R \& D. Bandung: Alfabeta, cv.

Yuliansyah, Harry. (2016). Uji Kinerja Pengiriman Data Secara Wireless Menggunakan Modul ESP8266 Berbasis Rest Architecture.Institut Teknologi Sumatra.Lampung

Gandapurnama, B. (2015). Separuh Pemicu Aksi Kejahatan di Bandung Gara - Gara Pelaku Tenggak Miras. Dipetik April 22, 2018, dari Detik News: https://m.detik.com/news/beritajawa-barat/3062810/

Quamila, A. (2017). 7 Bahaya Menenggak Banyak Alkohol dalam Waktu Singkat. Dipetik April 4, 2018, dari Hello Sehat: https://hellosehat.com/hidup-sehat/tips-sehat/pesta-miras-bahayamengonsumsi- banyak-alkohol/ 